\title{
FILOSOFIA
}

\section{Reseña Histórica del concepto de Metáfísica}

\section{ORIGEN DEL TERMINO METAFISICA}

La palabra Metafísica significa etimológicamente: más allá de la física, de la naturaleza (de meta = más allá; y fisis = naturaleza).

Este nombre tuvo un origen completamente casual. Aristóteles redactó numerosos apuntes y escritos breves, utilizados en sus clases sobre el ser y sus principios; objeto de la Filosofía Primera, como él la consideraba. Andrónicoide] Rodas (en el siglo éandes. C.), recopilador de la producción inédita de Aristóteles, puso la obra a continuación del libro de Física. Perou como larecha de fitulbercontrándose simple mente dividida en capítulos precedidos de números, aunque ordenados en un tratado, se la denominó: el escrito después de la Física, más allá de la Física: Meta-física.

El título no posee, pues, ninguna relación originaria con el contenido de la Metafísica, sino con el hecho fortuito y externo de haberse encontrado colocada después del libro de Física.

Esta denominación, sin embargo, a pesar de haber nacido de manera tan ocasional, ha sido acertada y feliz, lo que explica su persistencia en la historia.

LOS PRESOCRATICOS (siglo VI -mediados del siglo $V$ a. de J. C.)

Aristóteles es el primer pensador que sistematiza la Metafísica y la considera como disciplina independiente; pero eso no quiene decir que los problemas metafísicos no constituyan tema de meditación de los filósofos anteriores. 
Los pensadores presocráticos se plantean el problema del universo, ¿Qué es el cosmos? ¿de dónde procede todo? ¿posee la naturaleza una realidad distinta de la que percibimos? ¿cómo se encuentra constituída esa realidad trascendente? Las contestaciones a estas preguntas adquieren carácter especulativo y disperso, pues van unidas a la imaginación y a observaciones científicas en campos diversos: Matemáticas, Astronomía, Geografía, Meteorología, Fisiología. Pero en las meditaciones de los presocráticos alienta un impulso sistemático, y un anhelo de rebasar la experiencia cotidiana, considerada como fugaz, para encontrar el fondo metafísico que palpita en el origen de las cosas. Es actitud racional en la que se ha superado la alegoría y el mito. Es búsqueda de la sustancia, del devenir, de la unidad, o sea, de los principios del ser. Es, pues, investigación metafísica. Pero investigacion que, como hemos visto, va unida a observaciones de otra índole. Por eso, la Metafísica misma aun no constituye una disciplina independiente.

\section{LOS SOFISTAS Y SOCRATES (segunda mitad del siglo $V$ a. de J. C.)}

Los sofistas son maestros ambulantes que ejercen su actividad docente mediante honorario. No forman una escuela filosófica ni representan una doctrina definida. En lugar de la incógnita del universo, estudiada por los fíósolfos lanteriores, seeinteresana for los problemas del hombre y de la spciedad humaifaelfifornan probolemáticos campos hasta entonces considerados como seguros. Remueven así el dogmatismo ingenuo, divisando horicontes desconocidos y vírgenes: en la Eitica, De recho, Pedagogía, Gramática, Gnoseología. Pero no obtienen normas objetivas para la vida teórica y práctica, sino permanecen en el relativismo y subjetivismo. Sobreestiman el arte de la palabra y de la contienda. De ahí los ataques enérgicos e incesantes de Platón que les ha costado. ser calificados, hasta nuestros días, como dialécticos mañosos.

Frente a la posicićn negativa y relativista de los sofistas aparece la figura resplandeciente de Sócrates (469-399 a. de J. C.), defendiendo la validez universal de las normas éticas. La esfera de su enseñanza es la ciudad entera. Su misión fundamental es el educar. En Sócrates, como en los sofistas, la mirada del sujeto, proyectada antes hacia la naturaleza, gira sobre sí misma, tornándose el hombre en tema de meditación. Así clescubre el mundo de la conducta, el mundo de la Etica. Y ¿cómo se obtienen estas nuevas verdades sobre el hombre? Por medio del diálogo, de la conversación ciudadana. Porque en el fondo 
de todo hombre habita la verdad. Esa verdad que se encuentra como sumergida debe aflorar, salir a la superficie.

\section{PLATON (427-347 a. de J. C.)}

La doctrina platónica se desenvuelve en estadios sucesivos y múltiples, renovándose sin cesar en el transcurso de la vida del filósofo. Por eso, una comprensión exacta de su obra sólo puede obtenerse por vía genética a través de sus Diálogos. En la Academia los discípulos dividen su filosofía en tres grandes disciplinas —división esquemática que no abarca la plenitud del pensamiento platónico-: Física, Etica y Dialéctica.

La Física analiza el mundo de la naturaleza; objeto que había sido ya tratado por los pensadores presocráticos. La Etica estudia los principios y valores de la conducta humana; campo que había sido tema de las profundas meditaciones de Sćcrates. Ta Dialéctica investiga los principios y estructuras del pensamiento -concepto, idea, juicio, definición - y los principios del ser. Por tanto, es simultáneamente Lógica y Metafísica. Ambas disciplinas no se encuentran rigurosamente separadas, debido fundamentalmente a la significación equívoca de la Idea.

La Idea, en los Diálogos primeros, es el aspecto del contenido del concepto que mienta las cualidades primordiales de un objeto. Esta significación estrictamenteblógicácesatransmütada rensuna metafísica. El concepto, producto de un pfoceso pentsante se torna en esencia, en entidad autónoma, con existencia en sí.

Las Ideas constituyen un reino inmutable y eterno, perdurable en orden y en belleza. El mundo empírico, en cambio, se encuentra sujeto al devenir, al dolor y a la muerte. El hombre puede elevarse, ayudado por el amor, por el Eros, sobre las cavernas en que lo sumen el cuerpo y los sentidos, para contemplar el transfondo de la creación, los arquetipos de las cosas: el mundo de las Ideas.

\section{ARISTOTELES (384 -- 322 a. do J. C.)}

Aristóteles clasifica la filosofía en teórica, poética y práctica.

La Filosofía teórica posee su fin en el conocimiento, siendo la de mayor rango. Comprende la Física, las Matemáticas y la Metafísica. La Física se refiere a lo móvil de lo corpóreo - el movimiento de los cuerpos-i las Matemálicas a lo inmóvil de lo corpóreo - las relaciones cuantitativas, inmutables en cuanto tales-i la Metafísica a lo inmóvil y trscendente -los últimos principios del ser y lo divino-... 
La Fijosofía poética es el conocimiento referido a la creación estétíca. Su principio reside en la facultad artística; su fin en la obra creada. Es la teoría de la creación, a diferencia de la teoría referida a la acción. Aristóteles llega sólo a fundamentar la Poética.

La Filosofía práctica es el conocimiento dirigido a la acción. Su principio yace en la voluntad; su fin en la acción. Comprende la Etica, la Economía y la Política. La Etica versa sobre la conducta moral del individuo; la Economía sobre la constitucićn del hogar - la pequeña comunidad-; la Política sobre el Estado - là comunidad mayor--.

La Metafísica estudia los principios últimos del ser y lo divino.

Los principios que poseen carácter más general son la forma y la mâteria. La forma os la Idea platónica; pero ésta ya no existe en sí, separada de los individuales, sino sólo en ellos. (Ejemplo: la forma o esencia caballo existe sólo en los caballos individuales; si éstos de saparecen, desaparece también la forma, la esencia). La materia es la posibilidad o potencia. La forma es la, realización o actualización de esa potencia. (Ejemplo una estatua de mármol. La forma es la configuración artística de la estatua. Poro esa configuración —-forma- se ha realizado porque en el mármol - nateria-- existe esa posibilidad). No existe materia sin forma. La materia pura es mera abstracción. El movimiento es el tránsito de la posibilidad a la realidad. Lo que siendo inmóvil mueve no obstante todo, es la forma pura Y eterna, el espíritu absoluto, lo divino.

La Metafísica esJengAristóteles,eldimuatneamente, Ontología (tratado del ser) Teología (tratado de Dios). Estos campos no se encuentran rigurosamente diferenciados, evento que ha de provocar en lo sucesivo la confusión de ambas regiones.

\section{SAN AGUSTIN (354 - 430)}

En Seri Agustín se da un ansia ilimitada de saber absoluto, de verdad última. Tuvo que superar con este objeto el escepticismo de su época. En toda duda, sostiene hay algo indubitable: la duda misma. Se puede dudar de muchas cosas, pero algo permanece cierto: que se duda. Nadie puede dudar que duda, vive, recuerda, piensa, quiere. Estas son verdades de las que no puede dudar ningún escéptico. Verdades como $7+3=10$ existen independientemente de nuestra voluntad. Están en iuestro espíritu, pero no proceden de él, no son su producto. Su fundamento objetivo es Dios. Sólo su pariicipación en este fundamento eterno, en esta norma invariable, explica la concordancia entre los sujetos cognoscentes, diversos y cambiantes. 
San Agustín divide la filosofía, según el modelo platónico, en: Física, Matemática, Etica y Lógica. La Metafísica desaparece como disciplina independiente, y no debido a que la súbestime, sino a la inversa, por considerar que todo saber profundo es saber teológico, metafísico. El obieto de la Metafísica lo abraza por eso todo. El sentido perdurable de la vida humana y de la existencia cósmica no se obtiene en el saber mundano, sino en aquél que alcanza la raíz misma del ser, el transfondo espiritual de todo lo creado: el logos divino. Hacia él vuelve sin cesar la inquietud agustiniana: "Tú, oh Dios mío, nos has creado para tí, y nuestro cvorazón está inquieto hasta que descanse en tín".

\section{LA ESCOLASTICA (siglo IX - siglo XIV)}

La posición de San Agustín, impregnada de platonismo, repercute vigorosamente en la mística medieval. Más adelante, hacia el siglo X, comienzan a abrirse paso las corrientes aristotélicas, a través de sus reprezentantes árabes y judíos, hasta aldanzar su máximo esplendor en la filosofía de Santo Tomás de Aquino, el más alto representante de la filosofía escolástica.

A comienzos de la Edad Media scholasticus es el profesor —a veces también el alumno- de las siete artes liberales: trivium (Gramática, Dialéctica o l.ógica, y Rotórica) y cuadrivium tGeomelría, Aritmética, Astronomía y Música). Más tarde el término scholasticus se refiere a profeso-

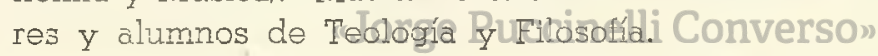

La Filosofía Medieval educa con energía autoritaria a los pueblos romano-germánicos en plena juventud. Trasmite el legado histórico, síntesis de la Antigüedad y del Cristianismo. La Filosofía concilia el saber y la fe, la razón y la verdad reve'ada. La preocupación del hombre medieval es el más allá: Dios. Ia filosofía en sus lineamientos generales, se encuentra subordinada a la Teología. Pero esta subordinación es considerada simultáneamente como su elevación, ya que adquiere mayor profundidad al ser impregnada por las verdades de la fe.

Para Santo Tomás (1225-1274) no existe oposición entre la revelación y la razón natural. Existen, es cierto, verdades reveladas que escapan a la razón humana que es limitada y finita; pero existe un saber de lo divino que puede ser fundamentado y explicado racionalmente, y que constituye tema de la Teología Natural, considerada como campo de la Metafísica. 


\section{LOS SISTEMAS METAFISICOS DEL. SIGLO XVII}

Los pueblos romano-germánicos, en la Edad Moderna, desenvuelven una enérgica voluntad de poderío, de ansia faústica de conquistar el mundo y dominar la naturaleza. Ya no es la región del más allá la que se encuentra en primer plano, sino el más acá: el hombre y la natura. El universo es explicado por causas naturales. La filosofía deviene en servidora de la ciencia.

La Filosofía Moderna se inicia en oposición a la escolástica; pero permanece un período bajo su influencia. Todavía para Descartes y Berckeley la existencia de Dios es más segura y evidente que la del mundo.

El siglo XVII es el de los grandes sistemas metafísicos, que encierran una concepción del universo, așí como la posición del hombre en el cosmos. No obstante, los pensadores de esta época no se consideran a sí mismos como metafísicos, sino como fílósofos de la naturaleza; metafísicos eran para ellos los escolástieos, los teólogos.

E.l avance extraordinario de las ciencias naturales trae la utonomía y predominio de la razón, que no recurre a verdades reveladas, sino a la evidencia de sus propias verdades. El pensamiento parte, según el modelo matemático, de algunas proposiciones evidentes, deduciendo mediante un procesor racional el resto de los conocimientos. La razón es tanto la capacidad de distinguir 10 verdadero de 10 falso, como la potencia areadora que "donfiege dricsineshidalashihassaltàs verdades. El pensamiento constructivo al avanzar siguiendo sus caminos reproduce el orden del universo ya que éste se encuentra estructurado racionalmente.

\section{LA EPOCA DE LA ILUSTRACION}

El espiritu se emancipa en el siglo XVIII de toda autoridad. El pensamiento racional, consciente de su triunfo, extiende su dominio no sólo por el mundo de la naturaleza, sino por todo el campo de lo humano. Ante el tribunal de la razón debe ser justificado todo lo existente: sociedad, economía, derecho, religión.

Un sano optimismo alienta las creencias. La armonía universal no sólo se revela en la regularidàd de los fenómenos naturales sino también en las normas de la vida humana. El hombre se siente elevado, gracias a su razón, por encima de los demás entes. Se cree en el progreso incesante del ser humano häcia la libertad y felicidad. Los hombres se encuentran unidos en una fraternidad universal. 
Ya no se emprende la construcción de grandes sistemas filosóticos. El pensamiento se expresa con frecuencia en formas breves, concisas y elegantes. No se parte de principios evidentes para deducir el conjunto del saber, sino de la observación de los hechos para encontrar la ley. Los principios, por tanto, no constituyen punto de partida, como en el racionalismo del siglo XVII, sino son ahora lo buscado. La razón más que un contenido de verdades inmanentes, es considerada como una energía, un hacer, un juntar y separar, que conforma el mundo empírico.

Un pensador de esta época, Christian Wolff, se inspira en la Filosofía Medieval al clasificar la Metafísica en general y especial. La Metafísica General es Ontología: tratado del ser. La Metafísica Especial comprende tres disciplinas: Teología, Psicología, y Cosmología, que se refieren respectivamente a las tres regiones del ser, divisadas por el pensamiento cristiano: Dios, Hombre y Naturaleza.

\section{KANT (1724-1804)}

Kant es el exponente filosófico más alto de la época de la Ilustración; pero en él yacen simultáneamente los gérmenes que han de conducir a un nuevo estilo de pensamiento.

A Kant se le ha considerado hasta época reciente como destructor de la Metafísica. Estalidea, ha sido promovida por el idealismo noe-kantiano, del último tercio del siglocXIXIll de orientaeión antimetafísica. La posición de Kant no posee en realidad este signo. La Metafísica se encuentra desacreditada en el siglo XVIII. El justifica las observaciones hechas contra la Metafísica especulativa y dogmática. Este tipo ha caducado; pero no por eso toda Metafísica. Kant se propone fundamentar el pensamiento metafísico con bases sólidas. La nueva Metafísica debe proceder con cautela suma. Por eso, antes de estudiar los principios del ser, es necesario analizar previamente el órgano con el cual van a ser investigados, o sea, las posibilidades y límites de la razón. Este es el planteamiento del criticismo. La crítica de la razón debe preceder a la Metafísica, no para destruirla, sino para ver cómo es posible.

El sistema de la razón se divide en: Metafísica de la Naturaleza -que trata de los principios a priori de la ciencia natural- y Metafísica de las costumbres - que se ocupa de los principios a priori del uso práctico de la razón. 


\section{EL IDEALISMO ALEMAN}

No obstante las reservas críticas de Kant, los pensadores más sobresalientes que lo suceden emprenden de nuevo el camino de la especulación. Son los filósofos del idealismo alemán del primer tercio del siglo XIX. Ellos representan un nuevo espíritu: la modalidad romántica. Se acentúa en esta época el predominio de la intuición, sobre el concepto, de lo dinámico sobre lo estático, de lo orgánico sobre lo mecánico, de las ciencias del espíritu - con sus métodos intuitivos que permiten alcanzar lo intimo de la realidad-sobre las ciencias naturales - con sus métodos mecánico-matemáticos--.

La dirección hacia los valores es tan pronunciada que no sólo son divisados en primer plano, sino que de ellos es abstraído el concepto de la realidad. El mundo empírico, con sus limitaciones espacio-temporales, se presenta como irreal. De nuevo insurge el menosprecio platónico por lo meramente empírico frente a la sublimación de la esfera absoluta de las Ideas.

Las Matemáticas aparecen como modelo de la filosofía, ya no en cuanto al método, pero sí por el valor apodíctico de sus conocimientos. La filosofía debe estar constituída también por conocimientos de validez universal y necesaria. Su fundamentación no puede provenir por eso de la experiencia, que sólo ofrece lo individual y contingente. El punto de partida es el yor para Fichte; lo absoluto, para Schelling; el ser puro, para Hegel. Biblioteca de Letras

\section{LA POSICION FOSITIVISTA}

\section{«Jorge Puccinelli Converso»}

Las ciencias naturales, en su desenvolvimiento, llegan a muy diferentes conclusiones que el idealismo romántico. Este desaparece hacia mediados del siglo XiX. La filosofía se desprestigia. El saber científico es considerado el único seguro. Los filósofos no se aventuran casi a presentarse como tales. La filosofía misma debe ser disciplina científica. Todavía a fines de siglo su campo se encuentra reducido al estudio de los supuestos de la ciencia: Lógica y Teoría del Conocimiento. Los temas capitales del hombre son abandonados a la ciencia o rechazados como incognoscibles o inexistentes.

Es la época del predominio positivista, fenomenalista. Se recela de todo lo que no se da empíricamente. Lo que no es susceptible de experiencia es negado como real. La experiencia está constituída por los datos de la percepción interna y externa, que el pensamiento -operación secundaria se limita a ordenar-. Objeto del conocimiento es el 
mundo fenoménico, integrado por los reflejos de las cosas en el sujeto cognoscente y determinado por la estructura gnoseológica de éste. El sujeto se encuentra encerrado dentro de su propia esfera, no puede conocer las cosạs como son en sí, independientemente de él, sino meramente sus resplandores. El pensador serio no debe, pues, rebasar el campo de la experiencia si no quiere caer en la especulación estéril. Hay que atenerse a los hechos, rechazando la Metafísica que pretende rebasarlos, llegar a la cosa en sí.

Las corrientes matafísicas de la segunda mitad de? siglo pasado, escasas y débiles, adoptan dos diversas posiciones fundamentales:

1. La Metafísica no puede rebasar el campo de la ciencia, porque ésta proporciona el único saber seguro. Pero hay una tarea que puede realizar: reunir en un todo armónico los resultados dispersos de las ciencias. La Metafísica elabora así la síntesis del saber científico. No rebasa, en esta forma el campo de la experiencia ni sus resultados se apartan de la ciencia.

2. La ciencia se detiene en los hechos, en el mundo fenoménico. Pero ella no proporciona el único saber existente. En el saber metafísico se llega a las cosas mismas, a su intimidad. La Metafísica es el saber de lo trascendente, de la cosa en sí.

\section{LA MET AFISICA EN BLISIGLO XX de Letras}

En este siglo (sळopfodidecelnrehàdinientorde) la Metafísica. Este nuevo auge ha sido facilitado por la confianza en la posibilidad del conocimiento trascendente. El saber no se detiene en el mundo fenoménico, sino se proyecta hacia las cosas mismas. Si éstas pueden ser conocidas como son en sí, también es posible captar sus principios. El camino de la Metafísica se encuentra así abierto.

Pero la. Metafísica contemporánea ha pasado por la problemática kantiana, $y$ hace suya su advertencia: no se debe proceder especulativamente, sino críticamente. Mas la crítica no se agota ahora en el análisis del conocimiento, sino es la cautela en el avance por el mundo de los objetos, el atenerse a ellos.

Sin embargo, aun no existe un concepto unívoco de la Metafísica. Los campos más diversos son considerados de su dominio. La historia los ha ido extendiendo, lo que acarrea una confusión cada vez mayor. Es. te hecho revela que aun no poseemos el esclarecimiento necesario sobre su esencia. 
SIGNIFICACIONES DE LA MET AFISICA

Bajo la palabra Metafísica se han entendido en el transcurso de la historia cosas muy diversas. Vamos a limitarnos a indicar algunas de las más importantes:

1. Metafísica es concepción del universo.

2. Metafísica es concepción del universo obtenida de la síntesis de los resultados científicos.

3. Metafísica es la disciplina de lo trascendente. Pero, la noción trascendente posee diversas significaciones:

a) Lo trascendente es la cosa en sí lo que se encuentra más allá del mundo fenoménico.

b) Lo trascendente es lo inteligible, lo que se halla más allá del mundo sensible, de la experiencia, y tiene que ser captado por el intelecto, por la razón.

c) Lo trascendente es lo irracional, lo que está más allá de la razón, o sea, lo incognoscible.

d) Lo trascendente es lo divino, lo que se encuentra más allá de la fisis, de la naturaleza. ente.

4. La Metafísica es la disciplina que estudia el ente en cuanto CRITICA Y CONCLUSION

Frente a esta multiplicidad de conceptos procuremos orientarnos, sin ademanes dogmáticós or fítimos, ya que son muy oscuros los fondos del problema.

1. Metafísica es concepción del universo. Pero no toda concepción del universo es Metafísica. Esta última es disciplina filosófica, elaborada racionalmente, fruto tardío de la evolución histórica. No así la concepción del universo. Ejemplo: los pueblos primitivos poseen concepción del universo, pero no Metafísica.

2. La definición que considera la Metafísica como síntesis de las ciencias, indica la nota que la diferencia de la concepción vulgar del universo. La Metafísica, entonces, no es cualquier concepción del universo, sino la obtenida sobre base científica.

Contestamos: la Metafísica no es síntesis de los resultados científicos. Puede encontrarse en relaciones con la ciencia, pero de ninguna manera depende de ella ni previamente necesita recoger sus resultados para sintetizarlos. La Metafísica posee su objeto propio, cuya generalidad rebasa el ámbito no sólo de las diversas ciencias considera- 
das aisladamente, sino también tomadas en conjunto. En principio, el ser, en su más amplia generalidad, no puede obtenerse de la mera síntesis de aspectos fragmentarios.

3. La definición que considera la Metafísica como disciplina de lo trascendente, es vaga. Porque lo trascendente es ontológicamente relativo. Una entidad es trascendente siempre en relación a otra. Por eso, es preciso indicar en qué sentido se toma el término trascendente. Al respecto las definiciones que siguen son más precisas:

a) La Metafísica estudia la cosa en sí. Pero de ninguna manera es nota característica de ella. También en las demás disciplinas filosóficas, en las ciencias, y aun en el conocimiento vulgar se llega a la cosa en sí.

b) La Metafísica estudia lo inteligible. Pero tampoco ésta es nota característica de ella. También las demás disciplinas filosćficas estudian lo inteligible, y algunas científicas -ejemplo: las Matemáticas-.

c) La Metafísica se ocupa de los problemas cuyas raíces se encuentran en lo irracional. Pero no sólo estudia los problemas irracionales, sino también los racionales. Ella se proyecta hacia su campo prescindiendo de las diferencias racionales e irracionales que puedan haber en él. Además, cada disciplina filosófica debs abordar los problemas irracionales que surqen de su seno. Esta posición es más adecuada que la de reunir fos diversos problemas de esta índole, inconexos y distantes, en una sola dísciplina:ien lià Metafísica." "

d) Lo divino, nos parece, no es objeto de la Mrtafísica. Existe una disciplina que lo estudia racionalmente: la Teología Natural. Puede ser cierta la afirmación que no se puede penetrar en las profundidades del ser, si previamente no se ha esclarecido el concepto de la divinidad. Eso implicaría la subordinación teórica de la Metafísica a la Teología; pero no por eso su identidad.

4. La Metatísica es, en su aspecto fundamental, Ontología: tratado del ser. En este sentido es Filosofía Primera: su campo lo abarca todo, se refiere a todos los entes en cuanto entes. Las demás disciplinas filosóficas estudian ya campos reducidos, son Ontologías regionales. 